\title{
An ARDL Approach on Crude Oil Price and Macroeconomic Variables
}

\author{
Seuk Yen, Phoong ${ }^{1}$, Seuk Wai, Phoong ${ }^{2 *}$ \\ ${ }^{1}$ Department of Mathematics, Faculty Science and Mathematics, Sultan Idris Education University, 35900 Tanjung Malim, Perak, \\ Malaysia \\ ${ }^{2}$ Department of Operations and Management Information Systems, Faculty of Business and Accountancy, University of Malaya, \\ 50603 Kuala Lumpur, Malaysia
}

\begin{abstract}
Objective - The removal of fuel subsidies by the Malaysian government in 2014 has been implement with the managed float system for fuel prices.

Methodology/Technique - This study investigates the impact of the managed floating system of crude oil prices on the Malaysian economy using ARDL approach by looking at macroeconomic variables such as inflation, economic growth and unemployment rates.

Findings - The results show that all of the variables have short lived relationship with oil prices whereby inflation and economic growth are positively related to oil prices. However, unemployment rate has a negative relationship with the changes of WTI crude oil prices.

Novelty - The major input in the economy of Malaysia contributes to a positive relationship between inflation and oil prices, whilst the contribution of Malaysia being an oil-producing country results in the positive relationship of economic growth and oil price. Likewise, as oil prices are high, the increase in demand results in increase in job opportunities. Lastly, the correlation test shows that inflation and economic growth have a high positive correlation while unemployment rate has a low negative correlation with oil price.
\end{abstract}

Type of Paper: Empirical.

JEL Classification: E10, E30, E39.

Keywords: ARDL; Crude Oil Price; GDP; Inflation; Unemployment.

\section{Introduction}

Throughout the years, Malaysians have been enjoying fuel subsidies by the government. This is one of the largest government subsidies in Malaysia as the fuel is sold below the market price. However, the high costs of subsidies have become a burden to the Malaysian government, which lead to its fiscal deficit (Abdul Hakim et. al., 2016; Zahiid, 2017).

\footnotetext{
* Paper Info: Revised: December 11, 2018

Accepted: March 15, 2019

* Corresponding author: Seuk Wai, Phoong

E-mail: phoongsw@um.edu.my

Affiliation: Faculty of Business and Accountancy, University of Malaya, Malaysia
} 
According to Fuel Malaysia (2016), the government argues that the fuel subsidies in Malaysia have failed to reach the intended targets as the subsidy was enjoyed by every citizens regardless of the class that they were in. The government was obliged to pay the prescribed amount, even to middle and upper classes as bigger cars tend to use more petrol than the smaller vehicles owned by the lower class. Thus, the new government of Malaysia has introduced a new policy in 2018 which removes the fuel subsidies on RON97, but maintains the price of RON95 at RM2.20.

According to Abeysinghe (2011), the extent to which the volatility of oil prices has an effect on open economies lies in whether the economy is a net oil importer or exporter. As Malaysia is a country that produces oil and is greatly involved in oil export and import, the fluctuations of crude oil prices with the managed float system has certainly had an impact on the economy. In addition, the slump of the crude oil price since 2014 has reduced its contribution to the oil-related income in Malaysia, which previously accounted for $30 \%$ of the government's budget (Say, 2017).

The perception of falling of oil prices has had a negative impact. However, lower oil prices could be good for consumers of oil or oil manufacturing sectors as it may help to reduce the cost of living such as lower transport costs and cheaper airline tickets. Thus, a decline in oil prices lead to lower inflation and higher spending with stagnant real wages. Furthermore, oil importers also derive benefit from reduced oil prices because they are able to buy the oil at a lower price. However, this situation implies that there is weak global growth.

The objective of this study is to investigate the impact of oil price with the managed floating system, on different macroeconomic variables in Malaysia, such as GDP, inflation and unemployment rates. This study is significant as it will provide suggestions for the policymaker to determine whether the implementation of the new system has been beneficial to the country.

\section{Research Methodology}

Economic growth, inflation, unemployment rates and oil price are used as the variables in this study. Log Gross Domestic Product (LGGDP) is used to represent economic growth, whilst the Consumer Price Index (CPI) represents the inflation rate in Malaysia. Furthermore, UNEMP stand for unemployment rate and Log WTI crude oil price represents the benchmark oil price used in this study. The data used in this study is taken from the U.S. Department of Energy and Bureau of Labor Statistics. The data of the Malaysia Consumer Price index (CPI), Gross Domestic Product (GDP) and Unemployment rate (UNEM) are taken from the Department of Statistics, Malaysia. The research design is as follows: the unit root test will be conducted to study the order of integration of the variables. The study proceeds by studying the short-term and long-term relationships by using ARDL Bound Test. Then, a correlation test is conducted to examine the strength of the association between the variables. Lastly, diagnostic checks will be conducted to test the adequacy of the models.

\subsection{Auto Regressive Distributed Lag (ARDL) Approach}

Autoregressive Distributed Lag (ARDL) is proposed by Pesaran et. al. (1999). It is also known as the bound testing method. This approach is used to study the long-term and short-term relationships between variables. It shows the existence of the equilibrium or stationary relationship among two or more time series data in which each of them can be individually non-stationary. It is applicable irrespective of the underlying variables being $\mathrm{I}(0), \mathrm{I}(1)$, or a combination of both. Moreover, the ARDL approach also helps to identify the co-integrating vector(s) as each of the underlying variables stands as a single equation of the long-term relationship. 


\subsection{Correlation Test}

The correlation test is used to investigate the association between two continuous variables. The sample correlation coefficient, also known as Pearson Product Moment correlation coefficient, $r$ is being estimated. The magnitude of the correlation test ranges between -1 to +1 , signifying the direction and the strength of the association between the variables.

\subsection{Diagnostic Checking}

According to Kuan (2008), diagnostic testing is an important step in time series modelling. It provides information regarding how the data might be modelled. It is also used to evaluate the residuals of the models, and to test the adequacy of the models. Breusch-Godfrey Serial Correlation LM test, Jarque-Bera (JB) test and ARCH test are used in this study to evaluate the residuals of the models.

\section{Results and Discussion}

The optimal number of lag length is determined by SIC for ADF test and New-West Bandwidth for PP test. According to the results of the unit root test, the p-values of LGWTI, LGGDP and CPI for both ADF and PP test do not statistically reject the null hypothesis of the existence of unit root in the series. This shows that there is unit root in the series of LGWTI, LGGDP and CPI. However, the results for the unemployment shows that the p-value is smaller than 0.05 for the ADF test and smaller than 0.01 for the PP test. Thus, the null hypothesis is rejected and it is concluded that unemployment has an integrated order of zero, $\mathrm{I}(0)$. By taking the first differenced form, both the ADF and PP tests indicate that the null hypothesis are rejected. It is therefore concluded that the series has a unit root and are integrated with one another I(1). In addition, the results of the ADF and PP tests, as shown in Table 1, provides consistent results as the PP test serves as a complementary test for the ADF test in order to confirm the order of integration of the variables.

\subsection{Bound Test (ARDL Approach)}

After conducting the unit root test using the ADF and PP test, it is found that UNEMP is $\mathrm{I}(0)$, while LGWTI, LGGDP and CPI are I(1). The bound testing method is conducted to answer the objective of the study that investigates the short-term or long-term relationship that exists between the parameters.

Table 1. ARDL Model on CPI and LGWTI.

\begin{tabular}{|c|c|c|}
\hline & Coefficient & t- statistic \\
\hline CPI (-1) & 1.001687 & 55.97910 \\
\hline LGWTI & 0.846090 & 0.724302 \\
\hline $\mathrm{C}$ & 0.647194 & 0.642562 \\
\hline Adjusted R-square & 0.997304 & \\
\hline Probability (F-statistic) & 0.0000 & \\
\hline \multicolumn{3}{|c|}{ Bound test for CPI and LGWTI } \\
\hline F-statistic & 3.655483 & \\
\hline
\end{tabular}

Table 1 shows that the adjusted R-square which has been adjusted from the number of predictors in the model reports the coefficient value of 0.997304 or $99.73 \%$ of CPI is being explained by past CPI (CPIt-1) 
and LGWTI. It is found that a $1 \%$ increase in the WTI will lead to 0.85 increase in CPI meaning these two variables are positively related. The F-statistic (Wald Test) of 3.655483 is found to be smaller than the lower bound value of $1 \%, 5 \%$ and $10 \%$ significance level. Thus, the null hypothesis that there is long-term relationship between CPI and LGWTI is rejected. It is therefore concluded that CPI has no long-term relationship with LGWTI. This finding is supported by Arinze (2011) who states that the inflation rate increases whenever petrol prices increase.

\subsubsection{Impact of LGWTI on LGGDP}

The findings of the estimated ARDL model on LGGDP and LGWTI are reported as follows:

Table 2. ARDL model on LGGDP and LGWTI.

\begin{tabular}{|c|c|c|}
\hline & Coefficient & T- statistic \\
\hline LGGDP(-1) & 0.896380 & 21.76872 \\
\hline LGWTI & 0.340715 & 6.090746 \\
\hline LGWTI(-1) & -0.240466 & -3.581296 \\
\hline C & 0.397848 & 2.630279 \\
\hline Adjusted R-squared & 0.989278 & \\
\hline Prob (F-statistic) & 0.000000 & \\
\hline Bound Test between LGGDP and LGWTI \\
\hline \multicolumn{2}{|c|}{3.168519} \\
\hline
\end{tabular}

The adjusted R-square of 0.989 shows that it is a good fit of the estimated model. Moreover, $98.92 \%$ of LGGDP can be explained by the past LGGDP (LGGDP (-1)), current LGWTI (LGWTI) and past LGWTI (LGWTI (-1). The F-statistic (Wald Test) of 3.168519 is found to be smaller than the lower bound value of $1 \%, 5 \%$ and $10 \%$ significance level. Thus, there is no long-term relationship between LGGDP and LGWTI meaning that LGGDP is not co-integrated with LGWTI.

\subsubsection{Impact of Oil Price on UNEMP}

Next, the relationship between UNEMP and LGWTI is examined using the ARDL model. The results are summarized in Table 3.

Table 3. ARDL Model on UNEMP.

\begin{tabular}{|c|c|c|}
\hline & Coefficient & T- statistic \\
\hline UNEMP(-1) & 0.820786 & 12.64272 \\
\hline LGWTI & -1.455215 & -1.932946 \\
\hline LGWTI(-1) & 1.440022 & 1.909930 \\
\hline C & 0.594968 & 0.972026 \\
\hline Adjusted R-square & 0.867176 & \\
\hline Probability & 0.0000 & \\
\hline \multicolumn{2}{|c|}{ Bound Test between UNEMP and LGWTI } \\
\hline
\end{tabular}




\begin{tabular}{|l|l|}
\hline F-statistic & 4.497290 \\
\hline
\end{tabular}

Table 3 indicates the estimated ARDL model to study the relationship between UNEMP and LGWTI. As shown in Table 3, the adjusted R-square of 0.867176 shows a good fit of the estimated model, signifying that $86.72 \%$ of UNEMP can be explained by UNEMP (-1), LGWTI, LGWTI (-1). This means that a $1 \%$ increase in LGWTI will lead to a $1.46 \%$ decrease in UNEMP. The F-statistic (Wald Test) of 4.497 is found to be smaller than the lower bound value of $1 \%$ and $5 \%$ and $10 \%$ significance level which is 6.84 and 4.94 respectively. Thus, the null hypothesis that there is long-term relationship between UNEMP and LGWTI is rejected.

The F-statistic of 4.497 is less than the lower bound value of 0.05 significance level, but greater than the upper bound value of 0.10 significance level. Therefore, the null hypothesis cannot be rejected at the 0.05 significance level, but can be rejected at the 0.10 significance level. This means that when there is an increase in oil price, the aggregate wealth and demand will increase which in turn creates more job opportunities that leads to the decline in unemployment.

\subsection{Correlation Test}

The strength of correlation is interpreted according to Mukaka (2012) while the significance of the relationship is studied via the p-value. There is a strong and positive relationship between LGWTI with CPI (0.849568); and LGWTI with LGGDP (0.880196). In addition, there is a weak and negative relationship between LGWTI and UNEMP (0.04337). Moreover, the p-value for all of the correlation between the parameter estimates is less than 0.05 significance level. Thus, the relationship between the variables are proved to be significant.

\subsection{Diagnostic Checking}

The Breusch-Godfrey Serial Correlation LM Test shows that all three variables, LGGDP, CPI and UNEMP have p-value of $0.6578,0.9877$ and 0.9256 respectively, which is greater than 0.05 . It is therefore concluded that there is no autocorrelation in these three models. The result of the Jarque- Bera test shows that the p-value of CPI and UNEMP is greater than 0.05. It is therefore concluded that the error term in these two models is normally distributed. However, the p-value of LGGDP is less than 0.05 meaning that the null hypothesis is rejected. This is related with CPI which does not normally have a big change compared to the base year. In addition, the unemployment rate of a country depends on the economic situation of the country. A country will not experience a big change in unemployment rates except when there is stock market issues, currency fluctuations or political issues. Thus, these two variables are normally distributed. However, LGGDP is the monetary value of all finished products and services that include private and public consumption, government outlay, investment and the foreign balance of trade.

\section{Conclusion}

In a nutshell, this study examines the impact of crude oil prices on the Malaysian economy following the implementation of the managed floating system of crude oil prices. An ARDL approach is adopted to study the impact of crude oil prices on the consumer price index, gross domestic product and unemployment rates. The results of the unit root test show that the consumer price index and gross domestic product have an integrated order of one, I(1) while unemployment has an integrated order of zero, I(0). Moreover, consumer price index and gross domestic product have a positive short-term relationship with WTI crude prices, whilst unemployment rates has a negative short-term relationship with WTI crude prices. A correlation test is used to study the relationship between oil prices and the three economic variables. Consumer price index and 
gross domestic product have a positive correlation with oil prices, while unemployment rates has a weak negative correlation with WTI.

\section{Acknowledgements}

The authors would like to acknowledge the financial support provided by the University of Malaya Research Fund Assistance (BKP) under project no. BK010-2017.

\section{References}

Abdul Hakim R., Ismail R., Razak A. and Azam N. (2016). Fuel Subsidy Reform in Malaysia: An Assessment on the Direct Welfare Impact On Consumers. International Postgraduate Business Journal, 8(1), 26-36.

Abeysinghe, T. (2001). Estimation of Direct and Indirect Impact of Oil Price on Growth. Economics Letters, 73(2), 147-153.

Arinze, P. E. (2011). The Impact of Oil Price on the Nigerian Economy. Journal of Research in National Development, 9(1), 211-215.

Kuan, G. M. (2008). Lecture on Time Series Diagnostic Tests, Institute of Economics Academia. Taiwan: Academia Sinica.

Mukaka, M. (2012). A Guide to Appropriate Use of Correlation Coefficient in Medical Research. 24.

Pesaran, M. H., Shin Y. and Smith, R. P. (1999). Pooled Mean Group Estimation of Dynamic Heterogeneous Panels. Journal of the American Statistical Association, 94(446), 621-634.

Say, T. L. (2017). Oil Price on the Mend but Not Ringgit. The Star. Available at: http://www.thestar.com.my/business/business-news/2017/01/07/oil-price-on-the-mend-but-not-ringgit/.

Zahiid, S. J. (2017). Weekly Petrol Price Announcements to Start March 29. The Malay Mail Online. Available at: http://www.themalaymailonline.com/malaysia/article/weekly-petrol-price-announcements-to-start-march-

29\#5OeDb0mJjEcZpOos.97. 